\title{
Review of Teaching the Skills That Matter
}

\author{
Kathy Olesen-Tracey, Illinois Community College Board
}

Teaching the Skills That Matter (TSTM) is an innovative and relevant training and professional development initiative funded by the Office of Career, Technical, and Adult Education and led by the American Institutes for Research.

Designed to support states and WIOA-funded grantees, the main component of the project is the TSTM Toolkit, which includes instructional models and curricular examples used to train teachers in the highly relevant content areas of civics education, digital literacy, financial literacy, health literacy, and workforce preparation.

The TSTM Toolkit, developed by adult education experts, is grounded in three research-based instructional approaches: problembased learning, project-based learning, and integrated and contextualized learning. These approaches enable teachers to provide in-depth instruction in the nine central skills that matter, skills that will be familiar to most practitioners. The nine TSTM central skills are: adaptability and willingness to learn, communication, critical thinking, interpersonal skills, navigating systems, problem-solving, processing and analyzing information, respecting difference and diversity, and self-awareness.

Located on the LINCS platform, the TSTM Toolkit is organized in a clear and easy-to-

navigate manner. Because the toolkit was created by educators for educators, it resonates with both teachers and learners. The resources available in the TSTM Toolkit are applicable for all levels of adult basic education and English language learning classrooms.

The toolkit begins with an overview and is organized around the five content/topic areas, each of which includes an issue brief, a case study, six standards-based lesson plans, and an annotated bibliography. The TSTM lesson plans offer adult education teachers the necessary support to meaningfully integrate the nine central skills into instruction.

The well-designed lesson plans in the TSTM Toolkit feature content that is highly relevant and engaging to adult learners. For instance, the civics education section of the toolkit includes a lesson plan on "First Amendment Rights" with a partner reading activity on the Montgomery Bus Boycott 
and Martin Luther King Jr.'s use of nonviolence. Another lesson plan is on the Flint water crisis. Equally rich content in the digital literacy section includes lessons on workplace safety and the appropriate use of social media. The financial literacy section provides background knowledge on purchasing a car and managing a budget while the lessons in the health literacy section engage learners in defining good health and critiquing health information on the internet. These lesson plans build knowledge and skills in the social sciences while also supporting and enhancing learners' digital literacy skills. Each of the lesson plans model best practices and provide guidance on developing future lessons at the local level.

Included in the "Other Tools and Resources" part of the TSTM Toolkit is an action plan template and guiding questions for integrated and contextualized learning, problem-based learning, and project-based learning. Teachers can use these guiding questions when applying the Teaching Skills That Matter processes to their existing curriculum. With this detailed guidance, coupled with the flexibility of design, the TSTM resources support educators to explore and apply fresh ways of working with adult learners.

The TSTM site also features brief videos of lesson implementation from actual adult education classrooms. The currently available videos focus on each of the three instructional approaches. The project-based video highlights the lesson "Eating Healthy on a Budget." The multi-level ESL classroom featured in the video is engaged in planning a healthy and affordable meal. This lesson provides instruction in English language acquisition, health literacy, and financial literacy while providing learners with a highly relevant learning experience. In the video on problem-based learning, we see a multi-level ESL class engaging in a real-world workforce preparation lesson on "Unmet Workplace Performance." The video on the integrated and contextualized instructional approach, features a class of intermediate- to highlevel $\mathrm{ABE}$ learners engaged in the financial literacy lesson on "Household Cash Flow" In this video, we see learners working collaboratively to discuss finances and decide how to manage money. Five additional classroom videos are planned on each of the TSTM topic areas

Moving instruction from theory to practice can be challenging. The TSTM Toolkit addresses this concern by including clear and concise sections that conclude with templates and tools to support transference of learning, making the toolkit easy to use by professional development trainers, adult education program managers, and instructors who seek opportunities for independent learning. There is even a tool for analyzing lesson plans to determine how the central skills can be incorporated into a teacher's regular curriculum.

With clearly outlined sections, the TSTM Toolkit as well as the classroom videos can be used at the local program level for staff development or through teacher training efforts statewide. As adult education strives to meet the needs of diverse learners and multi-level classrooms while preparing students to move into postsecondary education and sustainable employment, integrating the skills that matter into instruction creates a clear connection between content and real-world skill development that can improve outcomes for all learners. 